Bio - grafia. Escritos sobre la Biología y su Enseñanza. ISSN 2027

Edición Extraordinaria. p.p. 1488-1502

Memorias del VIII Encuentro Nacional de Experiencias en Enseñanza de la Biología y la Educación Ambiental. III Congreso Nacional de Investigación en Enseñanza de la Biología.

\title{
LA NUTRICIÓN CELULAR COMO UN MEDIO PARA EL APRENDIZAJE SIGNIFICATIVO DEL CONCEPTO CÉLULA
}

\section{CELLULAR NUTRITION AS A MEANS FOR MEANINGFUL LEARNING OF CELL CONCEPT}

Moreno Ortiz Angélica Lucía

Estudiante de Licenciatura en Biología, Universidad Distrital Francisco José de Caldas galmo88@gmail.com

\section{Resumen}

El concepto de célula es tratado en todos los niveles educativos, puesto que la célula siendo la unidad fundamental de todos los seres vivos (unicelulares o pluricelulares) desempeña tres funciones de vital importancia que son: relación (referente a la capacidad de percibir los cambios del medio externo y reaccionar ante ellos), nutrición y reproducción. Por tanto este trabajo se enfoca en este concepto a raíz de las dificultades en el aprendizaje de sus funciones y la de sus organelos en conjunto, probablemente por el uso de estrategias de corte tradicionalista durante el proceso de enseñanza- aprendizaje; para ello, se trabajó en la Institución Educativa Distrital Colegio República de Colombia, con estudiantes de grado sexto, realizando una intervención didáctica denominada "isabes cómo hacen los animales, las plantas y las bacterias para nutrirse y tener energía a partir de sus células?", con el fin de que lograran explicar el concepto con procesos cotidianos como la nutrición, en dicha intervención se aplicaron estrategias fundamentadas en el enfoque del aprendizaje significativo de Ausubel, y de acuerdo a los trabajos realizados y la evaluación diagnóstica final, se identificó los logros de aprendizaje.

Palabras claves: célula, nutrición, concepciones alternativas, propuesta didáctica

\section{Abstract}

The cell concept is treated in all levels of education, since the cell being the basic unit of all living beings (unicellular or multicellular) performs three vital functions are: relationship (referring to the ability to perceive the external environment changes and react to them), nutrition and reproduction. Therefore this work focuses on this concept because of the difficulties in learning their roles and their organelles together, probably by using traditionalist strategies during the teaching-learning process; for that, he worked at the Educational Institution District School Republic of Colombia, with sixth grade students, performing an educational intervention called "do you know how do animals, plants and bacteria to feed and take energy from their cells? ", in order to succeed in explaining the concept with everyday processes as nutrition, such intervention strategies based on the focus of meaningful learning of Ausubel were applied, according to the work done and the final diagnostic evaluation, achievement of identified learning. 
Bio - grafia. Escritos sobre la Biología y su Enseñanza. ISSN 2027

Edición Extraordinaria. p.p. 1488-1502

Memorias del VIII Encuentro Nacional de Experiencias en Enseñanza de la Biología y la Educación Ambiental. III Congreso Nacional de Investigación en Enseñanza de la Biología.

Keywords: cell, nutrition, alternative conceptions, didactic proposal

\section{Introducción}

La enseñanza del concepto de célula se evidencia en todos los niveles educativos, ya que es parte fundamental del aprendizaje sobre los organismos unicelulares y pluricelulares, a pesar de ello, los estudiantes no pueden realizar un aprendizaje significativo del concepto, ya que se les dificulta comprender la función de esta y la de sus organelos en conjunto, esto puede ser provocado durante el proceso de enseñanza - aprendizaje, entendiéndose esta como el espacio en el cual el principal protagonista es el alumno y el profesor cumple con una función de facilitador de los procesos de aprendizaje, además es el alumno quien construye el conocimiento a partir de leer, de aportar sus experiencias y reflexionar sobre ellas, de intercambiar sus puntos de vista con sus compañeros y el profesor. (Proceso de enseñanza aprendizaje, s.f.), por lo anterior, específicamente es el alumno quien logra generar un conocimiento evolucionado y con un mayor grado de complejidad acerca de un tema en particular.

Para que este proceso de enseñanza - aprendizaje sea efectivo y de forma apropiada, deben existir unas estrategias de enseñanza adecuadas, interés y motivación por parte del alumno como del profesor para lograr tal objetivo que es el aprendizaje. De acuerdo a esto, se presenta una propuesta didáctica basada en el enfoque del aprendizaje significativo y el uso de algunas estrategias de enseñanza docente propuesto por (Díaz, 1999). La teoría del aprendizaje significativo aportada por Ausubel se identifica con una frase descrita por él:

"Si tuviese que reducir toda la psicología educativa a un solo principio, enunciaría éste: de todos los factores que influyen en el aprendizaje, el más importante es lo que el alumno ya sabe. Hay que averiguarlo y enseñar de acuerdo con eso (Ausubel, 1963, 2000)." Citado por (Moreira, 2012).

Por lo tanto, el aprendizaje significativo se entiende como el proceso según el cual se relaciona un nuevo conocimiento o información con la estructura cognitiva del que aprende de forma no arbitraria y sustantiva o no literal. Esa interacción con la estructura cognitiva no se produce considerándola como un todo, sino con aspectos relevantes presentes en la misma, que reciben el nombre de subsumidores o ideas de anclaje (Ausubel, 1976, 2002; Moreira, 1997) citado por (Rodríguez, 2004). Es decir, como indica Moreira, 2012, la idea central de esta teoría Ausbeliana es su aprendizaje con significado y debe cumplir con tres requisitos, interacción entre conocimiento nuevo y previo, que este conocimiento no se aplique y aprenda de forma arbitraria, además, el estudiante debe tener la disposición de aprender y por último que el Aprendizaje significativo y aprendizaje mecánico están 
Memorias del VIII Encuentro Nacional de Experiencias en Enseñanza de la Biología y la Educación Ambiental. III Congreso Nacional de Investigación en Enseñanza de la Biología.

ubicados a lo largo de un mismo continuo, igualmente sugiere que este aprendizaje es progresivo.

Teniendo en cuenta como referente esta teoría, la propuesta surge a partir del trabajo realizado en la Institución Educativa Distrital Colegio República de Colombia en el grado sexto, debido a las dificultades en su aprendizaje; los estudiantes ven esta temática desde quinto grado, profundizando más desde grado sexto de secundaria y los siguientes niveles, por lo tanto, se esperaría un aprendizaje dada la reiteración de la temática. Sin embargo esto no sucede y los estudiantes siguen presentado dificultades puesto que no pueden realizar un enlace entre sus ideas y los conceptos que han aprendido en el aula, esto lo confirmar teniendo en cuenta el trabajo de Caballer \& Jiménez. (1992), pues ellos afirman que:

los y las estudiantes adolescentes tienen asumida la constitución celular de los seres vivos desde el punto de vista estructural, se ve seriamente limitada cuando se debe aplicar a situaciones indirectas o de aplicación del concepto. Pensamos que ello se debe a que la asociación teórica «ser vivo - estructura celular» repetida tantas veces a lo largo de la vida académica no ha sido aprendida significativamente."

Según lo anterior la intervención didáctica realizada a través de una pregunta problema "isabes cómo hacen los animales, las plantas y las bacterias para nutrirse y tener energía a partir de sus células?" busca solucionar parte de estas dificultades utilizando la nutrición celular como medio de aprendizaje, con el fin de que los alumnos puedan construir sus ideas de manera significativa, es decir, que las "concepciones alternativas" identificadas en una prueba diagnóstica inicial, puedan cambiar durante el proceso de enseñanza - aprendizaje con la implementación de esta Unidad Didáctica, concibiendo como tal estas ideas o concepciones como la relación entre el conocimiento científico y el conocimiento cotidiano, pero sin considerar al primero como más válido, concediéndole un estatus relativo en relación con otros tipos de saber (Cubero, 1994, p.31).

\section{Metodología}

Para generar la unidad se trabajó la IED Colegio República de Colombia, ubicada en la localidad de Fnantivá en la ciudad de Boaotó anlicado a estudiantes del arado sexto

ETAPA I: Se realizó un proceso de contextualización, teniendo en cuenta lo que propone (Fernandez, sf) se revisó el contexto sociocultural y familiar identificando las características de la institución, las familias, los alumnos y si hay niños que presentan NEES, adicional a esto se realizó una caracterización socioeconómica de los alumnos y contextualización del docente 
Memorias del VIII Encuentro Nacional de Experiencias en Enseñanza de la Biología y la Educación Ambiental. III Congreso Nacional de Investigación en Enseñanza de la Biología.

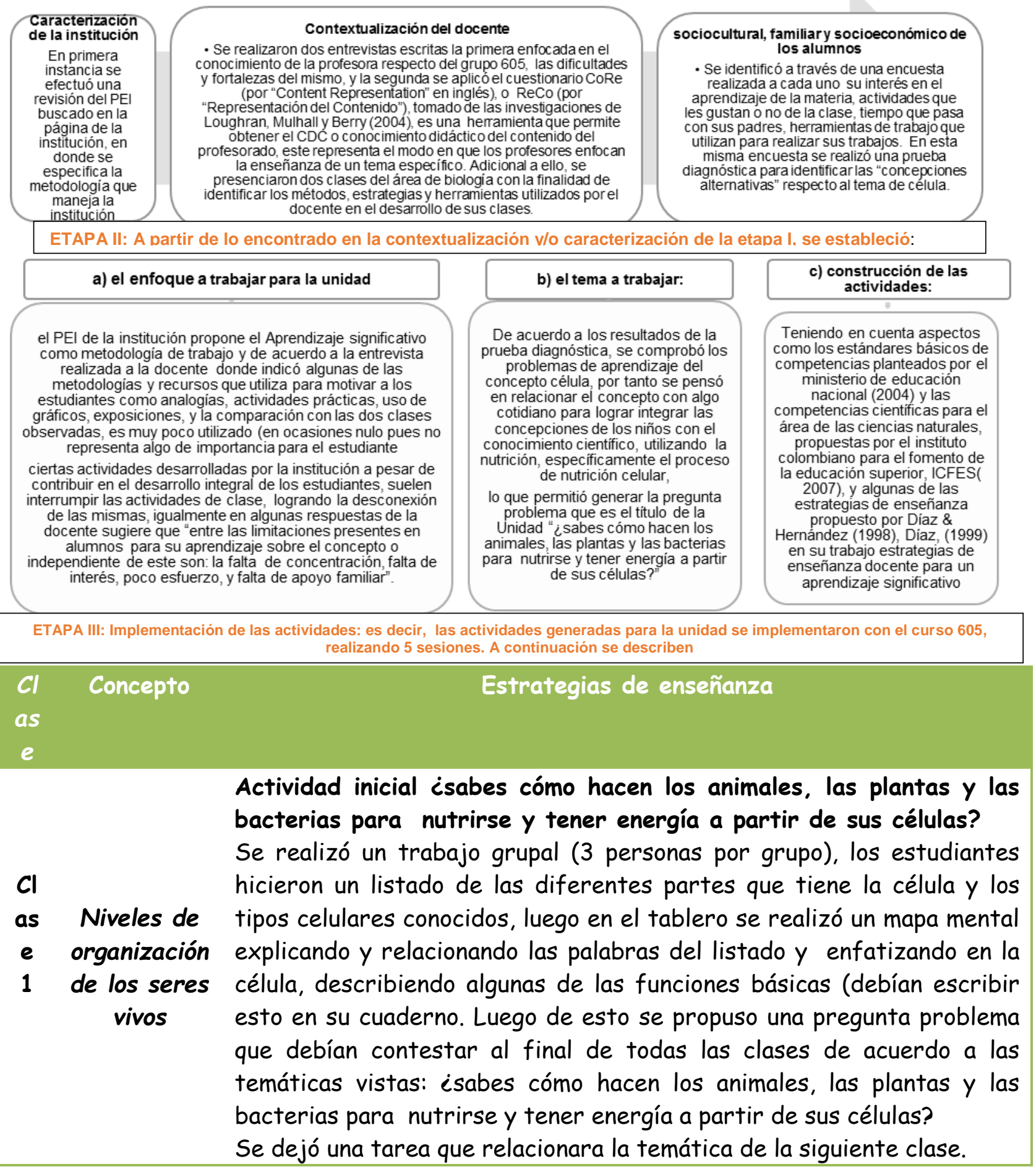


Bio - grafia. Escritos sobre la Biología y su Enseñanza. ISSN 2027

Edición Extraordinaria. p.p. 1488-1502

Memorias del VIII Encuentro Nacional de Experiencias en Enseñanza de la Biología y la Educación Ambiental. III Congreso Nacional de Investigación en Enseñanza de la Biología.

\begin{tabular}{|c|c|c|}
\hline $\begin{array}{c}C l \\
\text { as } \\
e \\
2\end{array}$ & $\begin{array}{c}\text { la membrana } \\
\text { como } \\
\text { transportad } \\
\text { or en la } \\
\text { Nutrición }\end{array}$ & $\begin{array}{l}\text { Actividad: ¿Cómo la membrana permite el paso de nutrientes } \\
\text { (moléculas) del exterior al interior de la célula? } \\
\text { Al comenzar la clase se dio una breve explicación de la pared celular } \\
\text { diferenciando las células que la presentan, luego se realizó un mapa } \\
\text { mental sobre el transporte de membrana pasivo, al mismo tiempo se les } \\
\text { presento unos videos con relación a esta temática Es decir esta } \\
\text { estrategia se cuenta como ilustraciones Díaz, (1999), (difusión simple, } \\
\text { facilitada y osmosis "conceptos como ambientes isotónicos, } \\
\text { hipertónicos e isotónicos") a medida de su explicación se realizara } \\
\text { esclarecimiento de los conceptos consultados a) Fluido, b) molécula, } \\
\text { c) concentración de moléculas en un fluido, d) gradiente de } \\
\text { concentración, i) difusión, j) osmosis (el tema de osmosis fue } \\
\text { complementado por la profesora en una clase en la que no estuve } \\
\text { presente) } \\
\text { Por último se entregó un documento con breve explicación y ejemplo } \\
\text { sobre ¿Cómo realizar un mapa mental? Para que ellos realizaran en la } \\
\text { tarea para la siguiente clase }\end{array}$ \\
\hline & $\begin{array}{l}\text { Nutrición } \\
\text { celular }\end{array}$ & $\begin{array}{l}\text { Actividad: ¿Nutrición celular por el transporte de membrana que } \\
\text { requiere energía? } \\
\text { Se realizó un trabajo grupal (6 grupos en total), a cada grupo se le } \\
\text { asigno un tema los cuales fueron: } 1 \text { Endocitosis, } 2 \text { Pinocitosis, } 3 \\
\text { Endocitosis medida por receptores, } 4 \text { Fagocitosis, } 5 \text { Exocitosis, 6: } \\
\text { Vesículas celulares, vacuola. } \\
\text { Se les dio un tiempo determinado para que lo hablaran, pidiéndoles que } \\
\text { entregaran una hoja con la respuesta al tema que les correspondió, } \\
\text { pasado este tiempo un representante de cada grupo debía explicar y en } \\
\text { cada intervención se aclaraba y se plasmaba en un mapa mental sobre } \\
\text { transporte de membrana que requiere energía (activo, endocitosis, } \\
\text { exocitosis) } \\
\text { En esta clase se alcanzó hasta los tres primeros grupos en la siguiente } \\
\text { se concluiría este tema y se anexará la función del citoesqueleto en la } \\
\text { nutrición (movimiento de la membrana celular), se dejó igualmente una } \\
\text { tarea debían contestar la pregunta inicial, ver unos videos en casa y } \\
\text { leer una lectura de nutrición heterótrofa y autótrofa donde se } \\
\text { relacionaron las plantas, los animales y los tipos de nutrición en las } \\
\text { bacterias }\end{array}$ \\
\hline
\end{tabular}


Bio - grafia. Escritos sobre la Biología y su Enseñanza. ISSN 2027

Edición Extraordinaria. p.p. 1488-1502

Memorias del VIII Encuentro Nacional de Experiencias en Enseñanza de la Biología y la Educación Ambiental. III Congreso Nacional de Investigación en Enseñanza de la Biología.

\begin{tabular}{|c|c|c|}
\hline $\begin{array}{l}C l \\
\text { as } \\
e \\
4\end{array}$ & $\begin{array}{l}\text { Funciones } \\
\text { básicas de } \\
\text { algunos } \\
\text { organelos } \\
\text { dentro de la } \\
\text { célula en la } \\
\text { nutrición }\end{array}$ & $\begin{array}{l}\text { Actividad: ¿En la nutrición celular puedo reconocer que organelos } \\
\text { participan en este proceso? } \\
\text { Continuación de la anterior clase con la participación del representante } \\
\text { de los grupos } 4,5 \text { y } 6 \text { (se presentó terminado el mapa mental para la } \\
\text { clase para facilitar las explicaciones) } \\
\text { Al terminar se realizó un mapa mental concluyente de la temática como } \\
\text { punto central la nutrición celular, donde se definieron las células } \\
\text { ubicando los organismos heterótrofos y autótrofos, y se relaciona su } \\
\text { nutrición con los tipos de transporte de membrana, identificando los } \\
\text { organelos que participan directamente de la nutrición celular como } \\
\text { lisosomas, fagosomas y vacuolas y de donde salen estos Aparato de } \\
\text { Golgi, retículo endoplasmático liso y rugoso } \\
\text { Se concluye que estos nutrientes al estar en citoplasma luego de la } \\
\text { digestión celular, tienen una fin y es la creación de proteínas, lípidos y } \\
\text { carbohidratos, dependiendo del organismo autótrofo y heterótrofo } \\
\text { para obtener energía } \\
\text { Por último se realizó la evaluación diagnostica I (quiz) contestando la } \\
\text { pregunta problema propuesta en la primera clase }\end{array}$ \\
\hline $\begin{array}{c}C l \\
\text { as } \\
e \\
5\end{array}$ & $\begin{array}{c}\text { Participación } \\
\text { de la célula } \\
\text { en procesos } \\
\text { de nutrición } \\
\text { en los } \\
\text { organismos }\end{array}$ & $\begin{array}{l}\text { Actividad Final Ahora si puedes responder ¿sabes cómo hacen los } \\
\text { animales, las plantas y las bacterias para nutrirse y tener energía } \\
\text { a partir de sus células? } \\
\text { Se realizó la evaluación diagnostica final donde debían contestar las } \\
\text { siguientes preguntas de forma individual: } \\
\text { 1. ¿Sabes cómo hacen los animales, las plantas y las bacterias para } \\
\text { nutrirse y tener energía a partir de sus células? De acuerdo a los } \\
\text { temas vistos en clase } \\
\text { 2. Dibuja la célula procariota y la célula eucariota animal y vegetal con } \\
\text { sus respectivos organelos. } \\
\text { 3. Explica cuáles son las funciones de la célula en los seres vivos, y } \\
\text { escribe la función básica de algunos organelos de la célula }\end{array}$ \\
\hline
\end{tabular}

\section{Resultados y Análisis}

Como se ha explicado se utilizó el aprendizaje significativo de Ausubel y las debidas estrategias llevadas a cabo en las clases para la implementación de la Unidad. Por tanto se logró identificar ciertos avances en los estudiantes. Para dar una organización se ubicaron en categorías (Tabla 1), donde se reflejó los avances respecto a la función de nutrición de la 


\section{Edición Extraordinaria. p.p. 1488-1502}

Memorias del VIII Encuentro Nacional de Experiencias en Enseñanza de la Biología y la Educación Ambiental. III Congreso Nacional de Investigación en Enseñanza de la Biología.

célula y su respuesta frente a la pregunta problema. De acuerdo a lo anterior, se reflejan en la Imagen 1 las respuestas textuales de los alumnos ubicados en su respectiva categoría, donde se muestra el desempeño en la prueba diagnóstica inicial, la evaluación diagnostica y la evaluación final; aclaro que el proceso de la nutrición celular se utilizó como medio de aprendizaje del concepto célula y de una función que esta cumple (la nutrición), por ende no se exigió el uso específico de los conceptos respecto a la nutrición celular sino se tuvo en cuenta la capacidad de relacionar ese proceso con la función misma de la célula, adicionalmente las estrategias de enseñanza docente empleadas (Tabla 2), permitieron mostrar un avance en el aprendizaje, como afirman Díaz \& Hernández (1999) pueden ser: antes "preinstruccionales", durante "coinstruccionales" o después "posinstruccionales" de un contenido curricular específico, ya sea en un texto o en la dinámica del trabajo docente, para esta unidad se utilizaron las tres, puestas en práctica en las actividades de clase.

\begin{tabular}{|c|c|c|c|}
\hline $\begin{array}{c}\text { I Poca o ninguna } \\
\text { evolución }\end{array}$ & II progreso lento & $\begin{array}{c}\text { III progreso } \\
\text { relativamente lento } \\
\text { (mejor } \\
\text { acercamiento) }\end{array}$ & $\begin{array}{l}\text { IV evolución } \\
\text { sobresaliente }\end{array}$ \\
\hline $\begin{array}{l}\text { Se ubicó a los } \\
\text { estudiantes que } \\
\text { en su respuesta } \\
\text { no se generó una } \\
\text { relación entre la } \\
\text { función de la } \\
\text { célula u el } \\
\text { organismo o no } \\
\text { contestaron } \\
\text { ninguna pregunta }\end{array}$ & $\begin{array}{l}\text { Se ubicó a los } \\
\text { estudiantes que } \\
\text { realizaron un } \\
\text { avance lento } \\
\text { respecto a la } \\
\text { función celular } \\
\text { pues no lograron } \\
\text { captar } \\
\text { concretamente la } \\
\text { idea que el } \\
\text { organismo necesita } \\
\text { de células en } \\
\text { procesos } \\
\text { nutrición de }\end{array}$ & $\begin{array}{l}\text { Se ubicaron los } \\
\text { estudiantes que } \\
\text { realizaron un mejor } \\
\text { acercamiento } \\
\text { respecto a la función } \\
\text { celular de nutrición } \\
\text { con el organismo, } \\
\text { pero no logran } \\
\text { explicar y enlazar } \\
\text { concretamente los } \\
\text { procesos de la } \\
\text { nutrición celular }\end{array}$ & $\begin{array}{l}\text { Se ubicaron los } \\
\text { estudiantes que } \\
\text { lograron incorporar a } \\
\text { sus ideas de manera } \\
\text { más organizada la } \\
\text { función de nutrición de } \\
\text { la célula en el } \\
\text { organismo, } \\
\text { identifican que esto se } \\
\text { da a través de procesos } \\
\text { que ocurren en la } \\
\text { nutrición celular }\end{array}$ \\
\hline $\begin{array}{c}\text { Preinstruccio } \\
\text {-nales }\end{array}$ & \multicolumn{2}{|c|}{ coinstruccionales } & $\begin{array}{c}\text { posinstruccional } \\
\text { es }\end{array}$ \\
\hline $\begin{array}{l}\text { Para este } \\
\text { caso se } \\
\text { explicó en la }\end{array}$ & \multicolumn{3}{|c|}{$\begin{array}{l}\text { se trabajaron en la segunda clase videos explicativos de } \\
\text { transporte de membrana pasivo y al mismo tiempo de } \\
\text { las explicaciones se utilizaban analogías para relacionar }\end{array}$} \\
\hline
\end{tabular}


Bio - grafia. Escritos sobre la Biología y su Enseñanza. ISSN 2027

Edición Extraordinaria. p.p. 1488-1502

Memorias del VIII Encuentro Nacional de Experiencias en Enseñanza de la Biología y la Educación Ambiental. III Congreso Nacional de Investigación en Enseñanza de la Biología.

\begin{tabular}{|lll|}
\hline primera clase & el transporte por ejemplo la difusión con "el desayuno al & temática pero \\
la propuesta & mezclar un líquido con azúcar", "respecto al gradiente & debido a los \\
de trabajo & de concentración pedí que cuatro estudiantes se & contratiempos \\
(Ver tabla de & hicieran a mi izquierda y tres a mi derecha e indicarles & "poco espacio \\
metodología & que yo como membrana en este transporte pasivo voy a & después del \\
etapa II)se & favor del gradiente de concentración" notando más & paro" no se pudo \\
indicó el & integración de los estudiantes. debido a los & mostrar, e \\
objetivo al & inconvenientes y el poco tiempo disponible en las & igualmente en la \\
que llegar & siguientes clases no se utilizó videos, dejándolos como & cuarta clase se \\
que ellos & tarea para la casa, otra estrategia es el uso de mapas & realizó un mapa \\
lograran & mentales, en el momento de explicar las temáticas en el & metal sobre \\
responder la & tablero, e igualmente como tarea debían elaborar un & nutrición celular \\
pregunta de & mapa mental sobre el tema visto, para esta estrategia & para integrar los \\
trabajo & no se utilizó mapas conceptuales, puesto que son más & temas \\
& dispendiosos y los estudiantes no saben realizar aun & \\
& organizaciones jerárquicas de la información, por tanto & \\
& los mapas mentales ofrecen más facilidad de & \\
& elaboración pero integrando los conceptos de forma & \\
& organizada, ya que su eficacia radica en que funcionan & \\
& de forma semejante a nuestra mente: utilizando & \\
& imágenes y asociaciones, es decir que trata de imitar & \\
& una función natural de nuestro cerebro. (gipuzkoa, s.f.) & \\
&
\end{tabular}

Imagen 1: cuadro con las preguntas en cada prueba identificadas como ( $A, B, C)$, cuadro con las respectivas respuestas de los estudiantes tomados como ejemplo, ubicados respectivamente en las categorías establecidas en este trabajo (I,II, III y IV).

\begin{tabular}{|c|c|c|}
\hline $\begin{array}{l}\text { A Prueba } \\
\text { diagnóstica } \\
\text { inicial: }\end{array}$ & $\begin{array}{l}\text { B Evaluación } \\
\text { diagnostica }\end{array}$ & C Evaluación final \\
\hline $\begin{array}{l}\text { Sabes que es } \\
\text { una célula y su } \\
\text { función? } \\
\text { ¿Quiénes } \\
\text { tienen células? y } \\
\text { Existen dos }\end{array}$ & $\begin{array}{l}\text { ¿Sabes cómo } \\
\text { hacen los } \\
\text { animales, las } \\
\text { plantas y las } \\
\text { bacterias para } \\
\text { nutrirse y tener }\end{array}$ & $\begin{array}{l}\text { ¿cómo hacen los animales, las plantas y las bacterias } \\
\text { para nutrirse y tener energía a partir de sus } \\
\text { células? } \\
\text { 2. Dibuja la célula procariota y la célula eucariota } \\
\text { animal y vegetal con sus respectivos organelos. } \\
\text { 3. Explica cuáles son las funciones de la célula en los }\end{array}$ \\
\hline
\end{tabular}


Bio - grafia. Escritos sobre la Biología y su Enseñanza. ISSN 2027

Edición Extraordinaria. p.p. 1488-1502

Memorias del VIII Encuentro Nacional de Experiencias en Enseñanza de la Biología y la Educación Ambiental. III Congreso Nacional de Investigación en Enseñanza de la Biología.

\begin{tabular}{l|l|l|l|}
\hline $\begin{array}{l}\text { tipos de células } \\
\text { (escribe cuales } \\
\text { son y dibújalas) }\end{array}$ & $\begin{array}{l}\text { energía a partir } \\
\text { de sus células? }\end{array}$ & $\begin{array}{l}\text { seres vivos, y escribe la función básica de algunos } \\
\text { organelos de la célula }\end{array}$ \\
\hline
\end{tabular}

Respuestas estudiantes No1 por categoría (Se muestran en algunas categorías citas textuales de ciertos estudiantes)

\begin{tabular}{|c|c|c|c|}
\hline & $A$ & B & $C$ \\
\hline$I$ & $\begin{array}{l}\text { Nuestro } \\
\text { cuerpo está } \\
\text { lleno de } \\
\text { ello }\end{array}$ & $\begin{array}{l}\text { se unen para darse } \\
\text { energía a través de } \\
\text { la sangre } \\
\text { conteniendo energía } \\
\text { y nutrientes }\end{array}$ & $\begin{array}{l}\text { Ellos se nutren a partir del agua y de lo que recibe } \\
\text { el cuerpo }\end{array}$ \\
\hline$I$ & $\begin{array}{l}\text { la célula es } \\
\text { un pequeño } \\
\text { microorgani } \\
\text { smo y su } \\
\text { función es } \\
\text { que ayuda } \\
\text { en cosas, } \\
\text { dibujando } \\
\text { una célula } \\
\text { procariota }\end{array}$ & $\begin{array}{l}\text { Los animales toman } \\
\text { H2O se nutren con } \\
\text { células se nutren } \\
\text { con nutrientes }\end{array}$ & $\begin{array}{l}\text { Ellos se nutren a partir del agua } \\
\text { 1)elios senutren a paxtir de el agan }\end{array}$ \\
\hline $\begin{array}{l}I \\
I \\
I\end{array}$ & $\begin{array}{l}\text { "que una } \\
\text { célula es un } \\
\text { pequeño } \\
\text { microorgani } \\
\text { smo que no } \\
\text { se puede } \\
\text { ver a } \\
\text { simple vista } \\
\text { su función }\end{array}$ & $\begin{array}{l}\text { "Las bacterias } \\
\text { utilizan el } \\
\text { transporte activo, } \\
\text { le piden ayuda a } \\
\text { otro organismo, las } \\
\text { plantas utilizan las } \\
\text { fotosíntesis, } \\
\text { reciben el sol por } \\
\text { las hojas y el agua }\end{array}$ & $\begin{array}{l}\text { "las células simplemente cogen los nutrientes que } \\
\text { consume el animal; Las bacterias utilizan el } \\
\text { transporte activo con ayuda de otro organismo; las } \\
\text { plantas se nutren por el sol, el agua, producen su } \\
\text { propio alimento" y para la función de la célula indico } \\
\text { "En los seres vivos la función de la célula es repartir } \\
\text { los nutrientes hacia todo el cuerpo (organismo), } \\
\text { Ribosomas Dan energía, Vacuola: Transportan } \\
\text { nutrientes", aunque el dibujo de la célula fue casi el }\end{array}$ \\
\hline
\end{tabular}


Edición Extraordinaria. p.p. 1488-1502

Memorias del VIII Encuentro Nacional de Experiencias en Enseñanza de la Biología y la Educación Ambiental. III Congreso Nacional de Investigación en Enseñanza de la Biología.

\begin{tabular}{|c|c|c|c|}
\hline & es ayudar" & & 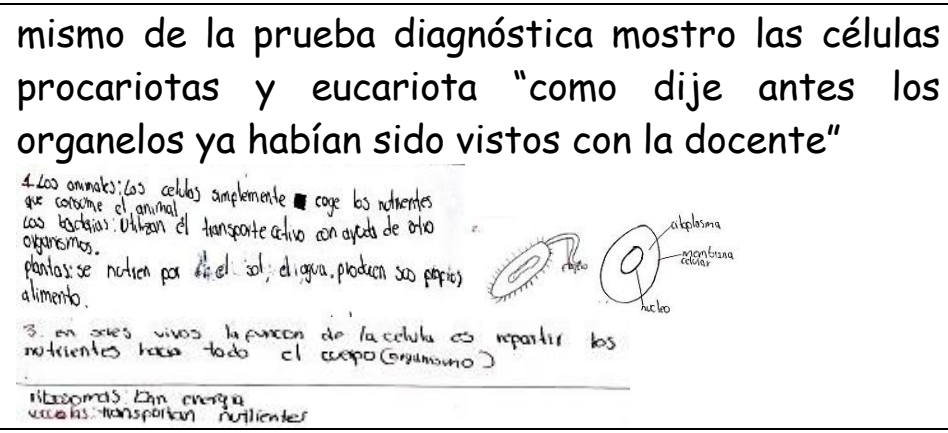 \\
\hline & $\begin{array}{l}\text { "todas las } \\
\text { células } \\
\text { tienen una } \\
\text { función } \\
\text { diferente } \\
\text { pero todas } \\
\text { funcionan }\end{array}$ & $\begin{array}{l}\text { Los animales no son } \\
\text { capaces de } \\
\text { almacenar su } \\
\text { alimento a través } \\
\text { de materia orgánica } \\
\text { que producen, los } \\
\text { demás seres vivos a } \\
\text { través de todos los } \\
\text { procesos de } \\
\text { transporte activo y } \\
\text { la nutrición y luego } \\
\text { con la digestión lo } \\
\text { convierten en } \\
\text { materia inorgánica; } \\
\text { Las plantas son } \\
\text { capaces de } \\
\text { almacenar su propio } \\
\text { alimento a través } \\
\text { de la fotosíntesis y } \\
\text { a través de la luz } \\
\text { solar toman su } \\
\text { energía; "Algunas } \\
\text { bacterias si son } \\
\text { capaces de } \\
\text { almacenar su propio } \\
\text { alimento a través } \\
\text { de materia } \\
\text { inorgánica y otros a }\end{array}$ & 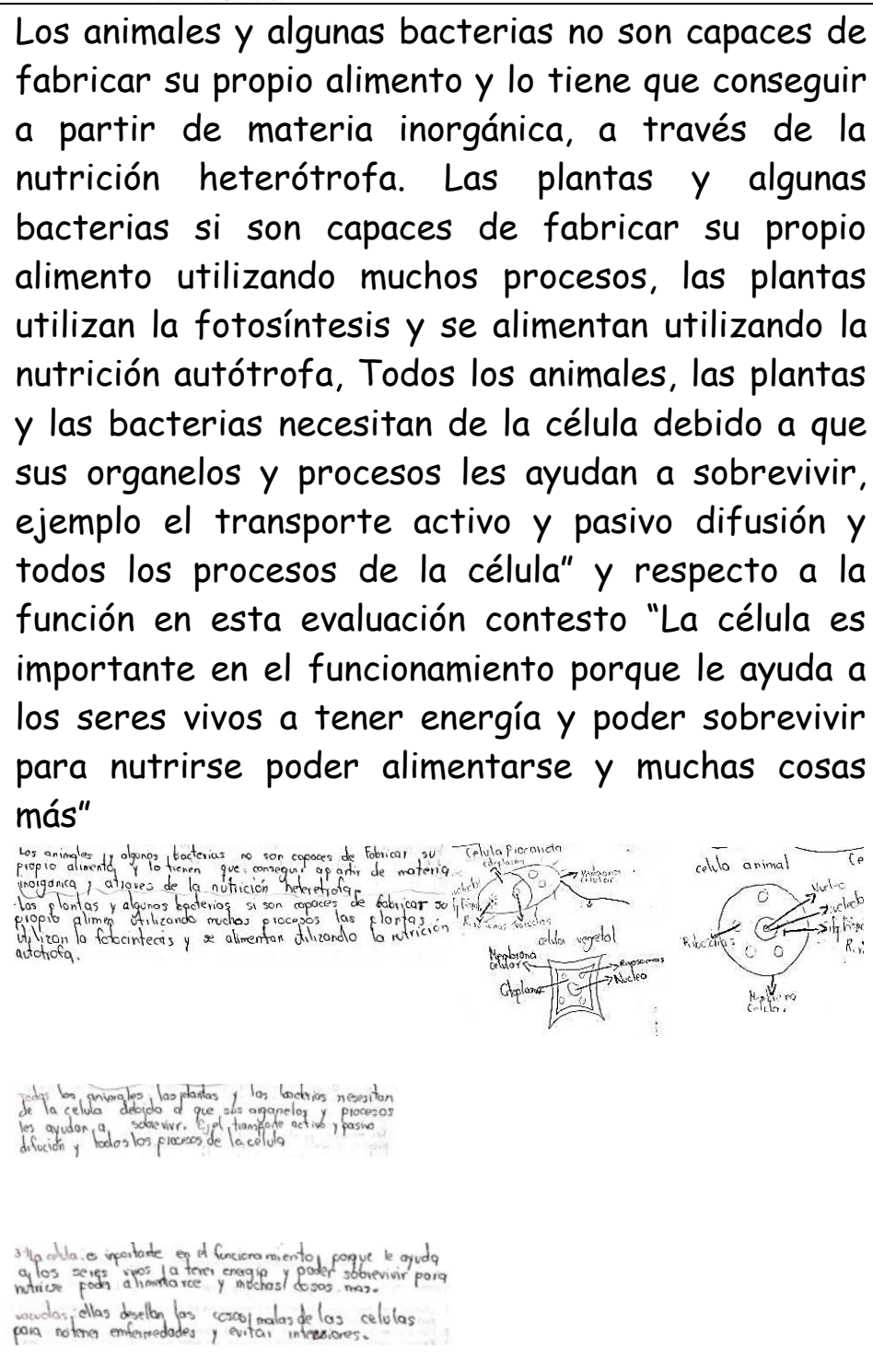 \\
\hline
\end{tabular}


Bio - grafia. Escritos sobre la Biología y su Enseñanza. ISSN 2027

Edición Extraordinaria. p.p. 1488-1502

Memorias del VIII Encuentro Nacional de Experiencias en Enseñanza de la Biología y la Educación Ambiental. III Congreso Nacional de Investigación en Enseñanza de la Biología.

\begin{tabular}{|l|l|l|}
\hline través de materia \\
orgánica de otros \\
seres vivos para \\
poder tener energía
\end{tabular} \mid

Respuestas estudiantes No 2 por categoría (Se muestran en algunas categorías citas textuales de ciertos estudiantes)

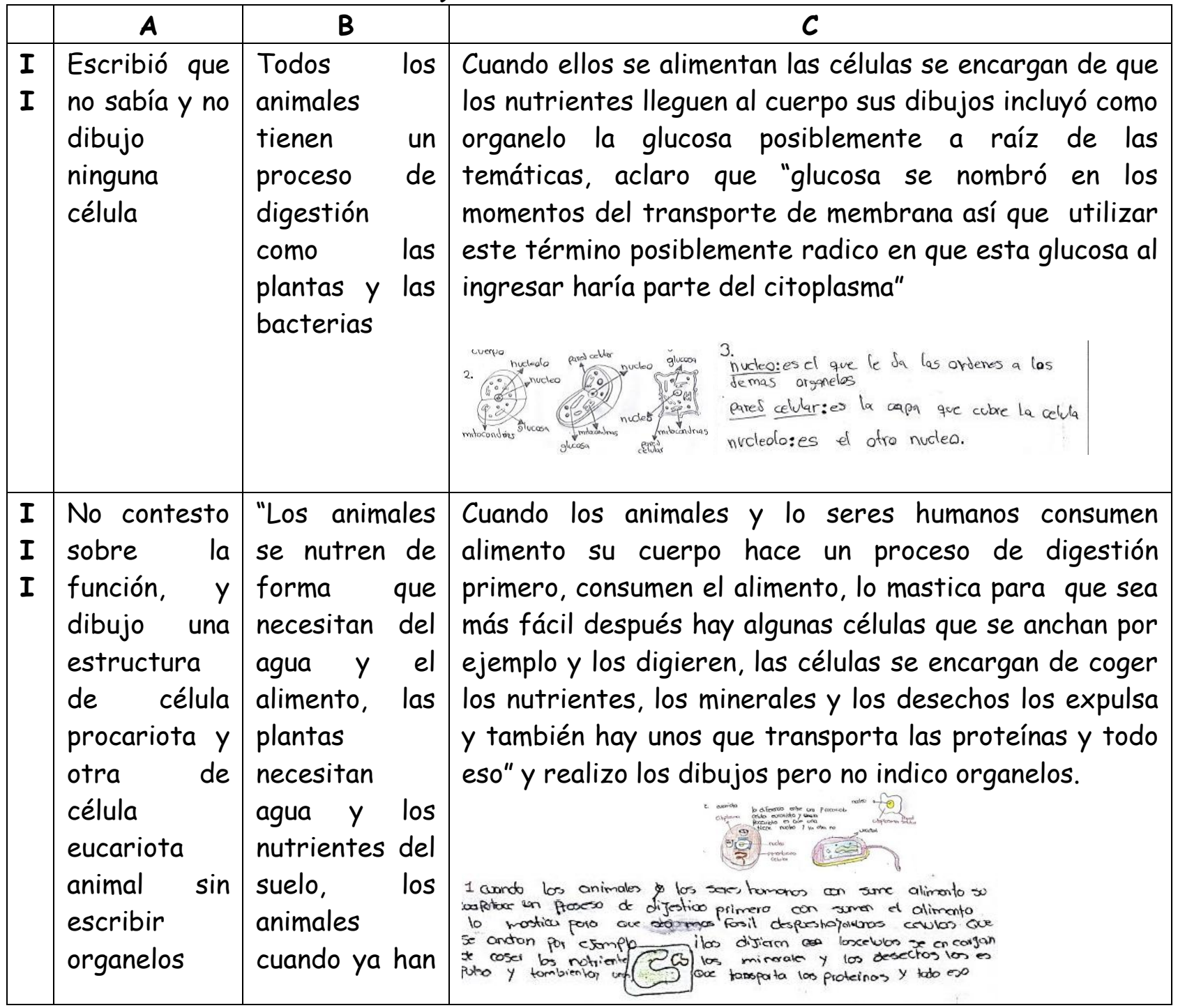


Bio - grafia. Escritos sobre la Biología y su Enseñanza. ISSN 2027

Edición Extraordinaria. p.p. 1488-1502

Memorias del VIII Encuentro Nacional de Experiencias en Enseñanza de la Biología y la Educación Ambiental. III Congreso Nacional de Investigación en Enseñanza de la Biología.

\begin{tabular}{|c|c|c|c|}
\hline & & $\begin{array}{l}\text { ingerido } \\
\text { alimento, las } \\
\text { células hacen } \\
\text { un proceso } \\
\text { para que todo } \\
\text { vaya en } \\
\text { forma" }\end{array}$ & \\
\hline$V$ & $\begin{array}{l}\text { una célula } \\
\text { creo que es } \\
\text { la función } \\
\text { del cuerpo y } \\
\text { sin ella no } \\
\text { podríamos } \\
\text { vivir" } \\
\end{array}$ & $\begin{array}{lr}\text { "No podrían } \\
\text { alimentarse y } \\
\text { se desnutren } \\
\text { y podrían } \\
\text { morir } r \text { sin } \\
\text { tomar y sin } \\
\text { comer o tal } \\
\text { vez hacen } \\
\text { nutrición, } \\
\text { para las } \\
\text { bacterias y } \\
\text { plantas r y } \\
\text { animales r } \\
\text { sobre el sol y } \\
\text { sombra" }\end{array}$ & 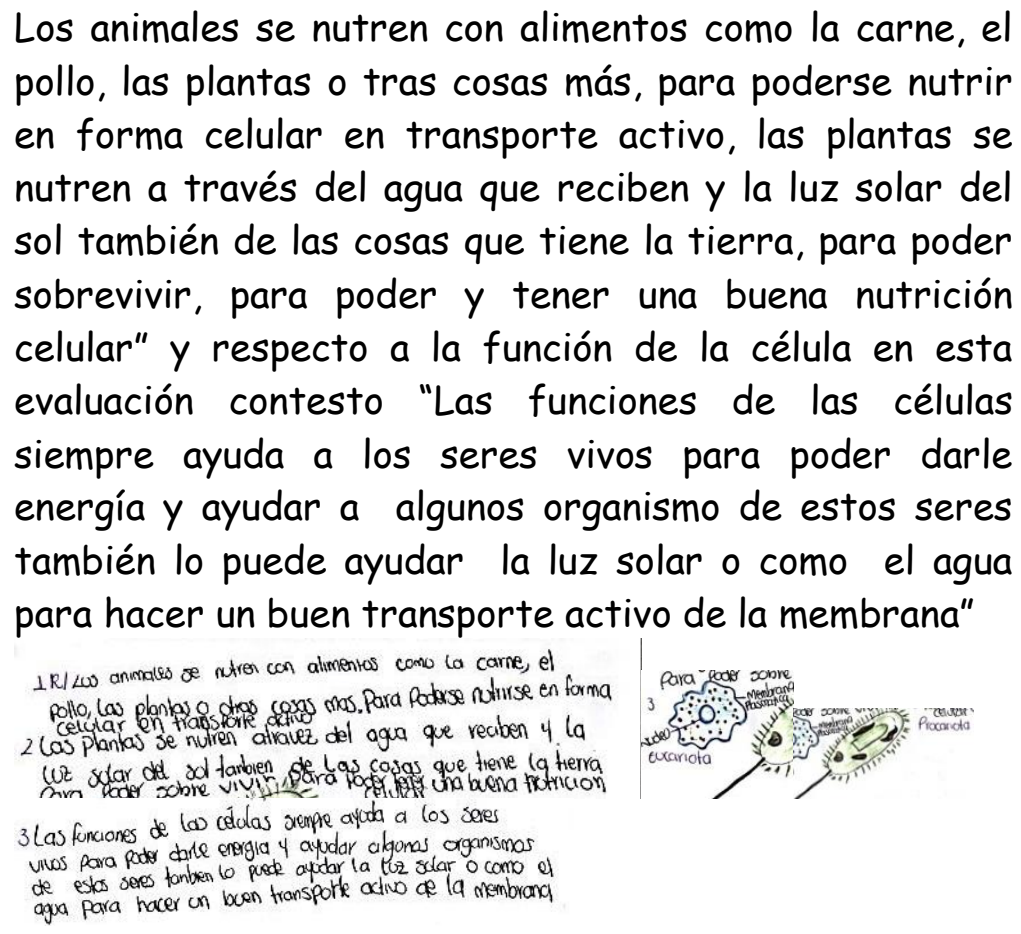 \\
\hline
\end{tabular}

Estos avances evidentemente confirman el modelo pedagógico utilizado y las estrategias anteriormente presentadas en la tabla 2, es decir, el aprendizaje significativo se evidencia

a raíz de las respuestas en las tres pruebas realizadas, comenzando con el primer requisito de esta teoría "la interacción cognitiva entre conocimientos nuevos y previos que es característica clave, (Moreira, 2012), en los estudiantes desde la segunda categoría en adelante se notó como tal esa interacción, puesto que sus conocimientos previos (algunos temas vistos dentro y fuera de la institución), se reflejaron en sus respuestas y naturalmente el progreso desde la primera prueba diagnóstica (ideas previas) hasta la prueba final; para el segundo requisito "en dicha interacción, el nuevo conocimiento debe 
Memorias del VIII Encuentro Nacional de Experiencias en Enseñanza de la Biología y la Educación Ambiental. III Congreso Nacional de Investigación en Enseñanza de la Biología.

relacionarse de manera no arbitraria y substantiva (no al pie de la letra, con lo que le aprendiz ya sabe y este debe mostrar una disposición para aprender" (Moreira, 2012).,

independientemente de no enfatizar en sus dibujos los organelos, lograron contestar a la pregunta problema de forma no arbitraria ni mecanizada, simplemente plasmaron sus ideas - "concepciones alternativas" (Cubero, 1994 p 31), con correcciones o mostrando mayor grado de relación entre el conocimiento científico y el cotidiano, además el grado de comprensión entre la función de la célula y el organismo sea pluricelular o unicelular radico evidentemente en su interés y participación; y por último el tercer requisito indica que "el aprendizaje significativo y aprendizaje mecánico están ubicados a lo largo de un mismo continuo, existe una interacción entre estos dos tipos de aprendizaje que no es una dicotomía, hay una zona "gris" donde ocurre el proceso de aprender "(Moreira, 2012), por tanto la evaluación se pensó en respuesta abierta, puesto que le permite al estudiante expresar lo que el mismo ha aprendido, tratando de evitar la aplicación memorística de los conceptos de forma mecánica, adicionalmente como se indicó antes el conocimiento no se debe adicionar de forma arbitraria así que muchas de las respuestas de los niños mostraron más un significado que una idea mecanizada, igualmente (Moreira, 2012) afirma que este aprendizaje es progresivo, y por tanto en un tiempo tan corto no debía esperar un grado de profundización elevado, no obstante la aplicación de las actividades contribuyo en mayor o menor medida a generar un "progreso".

Aclaro que la temática de los organelos no se profundizo debido a que esta había sido enseñada por la docente, pero de acuerdo (Moreira, 2012) "Siempre se debe considerar el conocimiento previo", no obstante en la primera clase se vio como tema introductorio, a pesar de ello sus dibujos carecían obviamente de estas ideas sobre los organelos, pero como se ha indicado, el punto central era comprobar ¿Cómo? Utilizando este enfoque y estrategias adecuadas se logra un aprendizaje con significado.

\section{Conclusiones}

- La Nutrición celular como medio de aprendizaje del concepto de célula se puede utilizar desde grados anteriores a secundaria, pero sin obligar al estudiante en aprender conceptos, sino más bien buscando a raíz de preguntas que ellos mismos relacionen 
Bio - grafia. Escritos sobre la Biología y su Enseñanza. ISSN 2027

Edición Extraordinaria. p.p. 1488-1502

Memorias del VIII Encuentro Nacional de Experiencias en Enseñanza de la Biología y la Educación Ambiental. III Congreso Nacional de Investigación en Enseñanza de la Biología.

sucesos cotidianos con las funciones mismas de la célula, esto contribuiría a que 1) durante el proceso logren identificar más las funciones y relacionar los organelos y 2) en los grados siguientes al realizar las profundizaciones a las temáticas no se obstaculicen a raíz de su mal aprendizaje.

- El aprendizaje significativo es evidentemente una buena herramienta en el proceso de enseñanza aprendizaje, adicionalmente el uso de estrategias adecuadas durante este proceso, ratifica que el docente debe asumir un papel de facilitador de los procesos de aprendizaje, dejando de lado la forma tradicional sin preocuparse por el progreso individual de los estudiantes.

\section{Bibliografía}

- Audesirk Teresa et al, (2003), Biología La Vida en la tierra - Capitulo 4 y Capitulo 5, Editorial Pearson Educación, 6 ed.

- Buitrago Reinosa María Alejandra, (2014), Enseñanza-aprendizaje del concepto de célula en estudiantes de básica secundaria, Universidad Nacional de Colombia, Facultad de Ciencias Exactas y Naturales Manizales, Colombia, tomado de: http://www.bdigital.unal.edu.co/20425/1/8412009.2014.pdf

- Caballer, M. y Jiménez, I. (1992). Las ideas de los alumnos y alumnas acerca de la estructura celular de los seres vivos. Enseñanza de las ciencias, Revista Enseñanza de las Ciencias 10(2), 172-180, tomado de: http://www.raco.cat/index.php/Ensenanza/article/download/39818/93185.

- Cubero Rosario, 1994, Concepciones alternativas, preconceptos, errores conceptuales ¿Distinta terminología y un mismo significado, Departamento de Psicología Evolutiva y de la Educación, Básica y Metodológica, Universidad de SevillaInvestigación y escuela No 23,1994

- Díaz F. \& Hernández. Rojas G, (1998.) Estrategias docentes para un aprendizaje significativo. Una interpretación constructivista. Segundo capitulo. Editorial MC Graw Hill 
Bio - grafia. Escritos sobre la Biología y su Enseñanza. ISSN 2027

Edición Extraordinaria. p.p. 1488-1502

Memorias del VIII Encuentro Nacional de Experiencias en Enseñanza de la Biología y la Educación Ambiental. III Congreso Nacional de Investigación en Enseñanza de la Biología.

- Proceso de enseñanza aprendizaje, (S.F). tomado de http://www.marista.edu.mx/p/6/proceso-de-ensenanza-aprendizaje

- Fernández-Espada Ruiz Carlos, (S.F.), Como elaborar unidades didácticas. Definición de unidad didáctica, tomado de: http://www.eduinnova.es/dic09/UD.pdf.

- GIPUZKOA, S.F., CURSO BASICO DE MAPA MENTALES, tomado de: http://blogs.ujaen.es/biblio/wpcontent/uploads/2014/04/manual_mapas_mentales.pdf.

- Instituto Colombiano para el Fomento de la Educación Superior-ICFES-, (2007), Competencias del ICFES tomado de: http://www.colombiaaprende.edu.co/html/competencias/1746/articles335459_pdf_2.pdf.

- Ministerio de Educación Nacional República de Colombia (2004), Estándares Básicos de Competencias en Ciencias Naturales y Ciencias Sociales), tomado de: http://www.mineducacion.gov.co/1621/articles-81033_archivo_pdf.pdf.

- Ministerio de Educación de Perú, (S.f.), Estrategias de Enseñanza-Aprendizaje, tomado de: $\quad$ http://www2.minedu.gob.pe/digesutp/formacioninicial/wpdescargas/bdigital/033 estrategias de ensenanza_y aprendizaje.pdf

- Moreira Marco Antonio, (2012), Aprendizaje significativo, campos conceptuales y pedagogía de la autonomía: implicaciones para la enseñanza, Aprendizagem Significativa em Revista - V2 (1), pp. 44-65, tomado de: http://www.if.ufrgs.br/asr/artigos/Artigo_ID24/v2 n1 a2012.pdf.

- Porto Andión Alejandro, (S.F)., Curso de Biología - Fisiología Celular, tomado de: http://www.bionova.org.es/biocast/documentos/tema12.pdf.

- Rodríguez Palmer Ma Luz, (2004), La teoría del aprendizaje significativo, Centro de Educación a Distancia (C.E.A.D.), tomado de: http://cmc.ihmc.us/papers/cmc2004290.pdf. 
